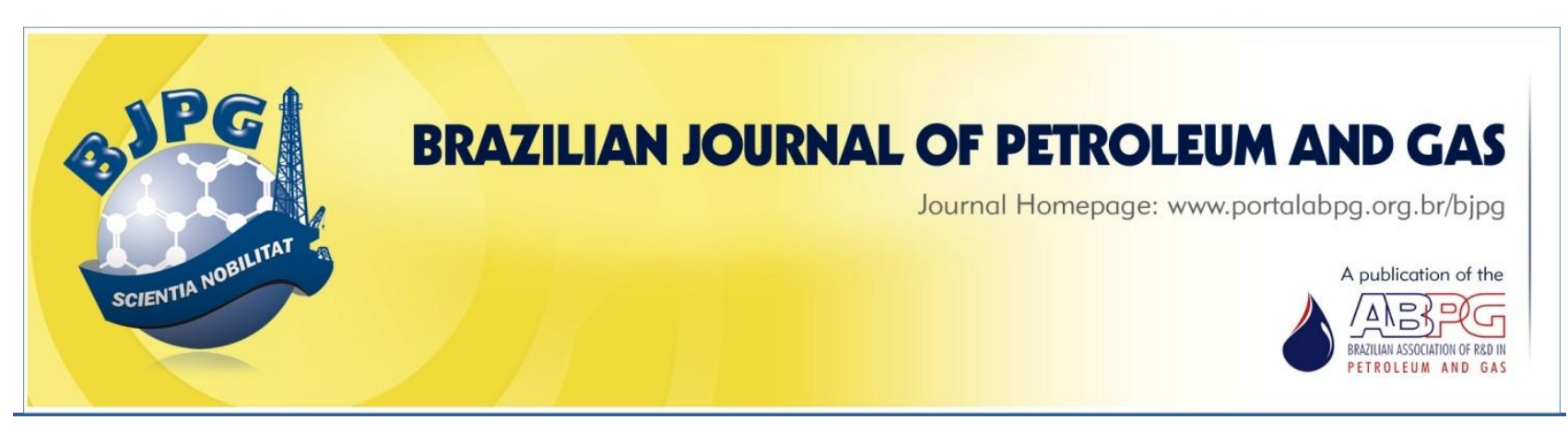

\title{
EFFECT OF INORGANIC SOLIDS CONTENT IN PETROLEUM SAMPLES ON SLUDGE FORMATION AND ACCUMULATION
}

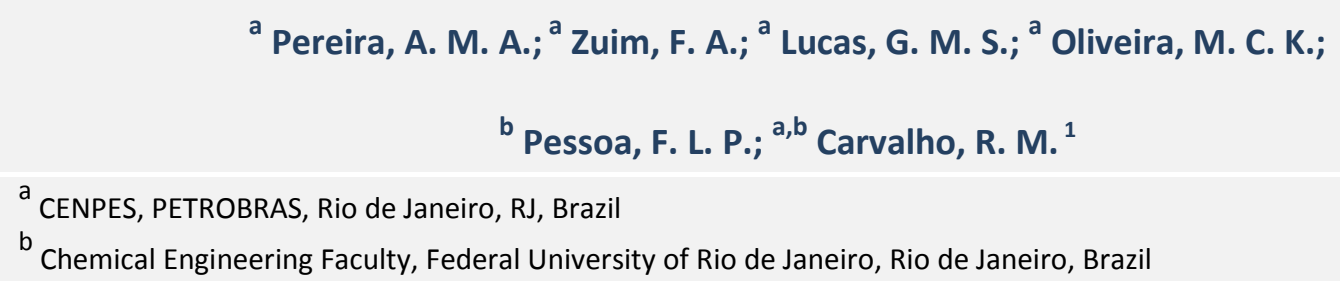

\section{ABSTRACT}

Petroleum and sludge samples were analyzed to establish a possible relationship between the solid content in petroleum and residue formation. Petroleum and sludge samples from crude oil production systems ( $A$ and $B$ ), storage facilities $(C)$ and refineries $(D, E$, and $F$ ) were analyzed to propose a possible explanation for residue formation and accumulation. In all samples, high concentrations of inorganic materials were observed. The characterization data were discussed and a mechanism of sludge formation was proposed in this work. It was possible to determine a direct correlation between solid contents in petroleum and residue formation.

\section{KEYWORDS}

sludge; inorganic solids; characterization

\footnotetext{
${ }^{1}$ To whom all correspondence should be addressed. Address: CENPES - PETROBRAS, Av. Horácio de Macedo 950, Cidade Universitária, Ilha do Fundão, Rio de Janeiro - RJ, Brazil, Zip code: 21949-900.

Telephone / Fax: +55 2121627516 | E-mail: $\underline{\text { rmc@petrobras.com.br }}$ doi:10.5419/bjpg2014-0003
} 


\section{INTRODUCTION}

The composition of sludges found in the petroleum industry is related to the deposition of wax (Martos et al., 2010) and asphaltene (RamirezJaramillo et al., 2006), presence of inorganic solids (Wang et al., 2010), or formation of stable emulsions (Oliveira et al., 2010). Emulsions are usually associated with the presence of polar compounds in petroleum, such as asphaltenes and naphthenic acids, particularly sodium or calcium naphthenates (Brons \& Varadaraj, 2007; Gafonova \& Yarranton, 2001; Yang et al., 2007). Moreover, some studies report that inorganic particles also play an important role in sludge formation and emulsion stability (Cloud et al., 2010; Kilpatrick \& Sullivan, 2002; Sztukowski \& Yarranton, 2005; Yan et al., 2001).

In this context, some investigations have been undertaken using model systems (Hannisdal et al., 2006; Kilpatrick \& Sullivan, 2002), comprising commercial or real particles dispersed in solvents. The results obtained in all studies show the contribution of fine particles in emulsion stability. Correlations between particle size and stability have also been proposed (Kilpatrick \& Sullivan, 2002; Yan et al., 2001). In addition, interaction of inorganic particles with asphaltenes causes synergic effects in emulsion stabilization.

On another departure, there have been some reports focusing only on the impact of solid contents in emulsion stability (Cloud et al., 2007; Marsh \& Poindexter, 2009; Poindexter et al., 2005). Parameters such as particle size, wettability, and any other solid properties or interactions with other polar species present in petroleum have not been considered.

The impact of sludge accumulation in processing is mainly due to the limited capacity of the vessels used in oil separation and as storage tanks. Sludges are also a problem in flow assurance, which could be minimized if the rheological properties of the fluids and their relationship with the chemical properties of the medium are known. Dynamic oscillatory measurements can be performed in order to characterize the network structure of dispersions (Svetlana, 2009; Torres et al., 2007). The viscous and elastic responses of these systems can be quantified through the oscillatory method. The basis of these measurements is the application of a sinusoidal strain $\gamma^{*}=\gamma_{0} e^{i \omega t}$, with frequency $\omega$. The sinusoidal stress in the sample $\tau^{*}=\tau_{0} \mathrm{e}^{\mathrm{i} \omega \mathrm{t}+\delta}$ is then measured. For viscoelastic systems, the stress and strain are out-of-phase $(\delta)$. The response of the system can be translated in terms of the complex modulus $\left(G^{*}=\tau^{*} / \gamma^{*}\right)$, from which a viscous component $\left(G^{\prime \prime}\right)$ and an elastic component $\left(G^{\prime}\right)$ are calculated, as follows:

$G^{*}=\frac{\tau^{*}}{\gamma^{*}}=\frac{\eta i \omega}{1+i \lambda \omega}=G^{\prime \prime}+i G^{\prime \prime \prime}$

The extent of the network formation can be inferred from these measurements, since the more structured the network, the more the system behaves as an elastic solid. The yield stress represents the limit shear stress to disturb the system, from a linear to a non-linear viscoelastic regime. Yield stress values can also be obtained from oscillatory tests.

The solid content in petroleum is not high enough to justify the residue quantities commonly found in some equipments. To have a better understanding of the impact of solids in the sludge formation, some residue samples were collected from systems where sludges were more frequently observed. These samples were submitted to chemical and rheological characterization. Solid contents in petroleum were determined based in different methods and potential formation of emulsions was also investigated to assist the understanding of sludge accumulation.

\section{MATERIALS AND METHODS}

\subsection{Materials}

Eight different petroleum samples were used to determine the solid content (identified as samples 1 to 8). Sludge samples from petroleum production systems (identified as $A$ and $B$, from the same oil production system; sample $A$ from the separator vessel and sample $B$ from the oil treater), storage facilities (C) and refinery (D, E, and F; sample D was collected from the separator tank and samples $E$ and $F$ from the desalter) were used in this study. Solvents n-hexane, toluene, and dichloromethane were purchased from VETEC and used without further treatment. 


\subsection{Solid content determination}

Two procedures were followed to measure the solid content in the petroleum samples:

- Modified ASTM 4807-05 (a 0.2- $\mu$ m PTFE membrane was used instead). In this procedure, 10 grams of petroleum were dissolved in $100 \mathrm{~mL}$ of toluene and heated to $90^{\circ} \mathrm{C}$ during 15 minutes. The solution was filtered out and the membrane was dried and weighed;

- Ultrasound-based procedure: A mixture of sample and petroleum prepared on a 1:40 mass proportion was submitted to sonication in an ultrasonic processor (Bandelin 3200, with a MS-73 probe) for 30 minutes. The final solution was filtered out on the $0.2-\mu \mathrm{m}$ PTFE membrane, the residue was washed out with toluene and dried, and the membrane was weighed.

\subsection{Solid membrane analysis}

A Stemi 2000 C stereomicroscope was used to analyze the membrane residue, with imagecapturing systems $(50$ and 100 times magnification). The membranes were also analyzed by Scanning Electron Microscopy and Energy Dispersive Spectrometry (SEM/EDS), to obtain a sharp chemical visualization and identification.

\subsection{Chemical characterization of sludge samples}

A previous centrifugation procedure was applied to samples $C$ and $D$ to separate the solids. It was carried out at $12,000 \mathrm{rpm}(15,455 \mathrm{~g})$ for 30 minutes. The solids separated in this pre-treatment were analyzed as described below. Samples A and $B$ were used without any previous treatment. This procedure was based on solid-liquid soxhlet extraction, as previously reported by Oliveira et al. (2010). The samples were fractionated and identified as organic nonpolar (in n-hexane extract), organic polar (in toluene and dichloromethane extracts), and inorganic fractions (insoluble extracts obtained after extraction). The extraction procedure was sequential and the solvents used were $\mathrm{n}$-hexane, toluene, and dicloromethane, in this order. The extracts (soluble and insoluble) were evaporated and weighed. All extractions were carried out in duplicates for each sample. The extracts were analyzed by:

- Termogravimetric analysis (only for toluene extract from sample A). The mass loss in different temperature profiles was evaluated as reported in the literature (Teixeira and Gonçalves, 2001), with a TG-951 cell linked to a TA-2100 control model, from TAInstruments.

- Infrared analysis of soluble extracts. The organic composition of the different fractions obtained in the extraction procedure was analyzed with an Avatarmodel Nicolet spectrometer.

- X-Ray fluorescence and diffraction of insoluble fractions: The inorganic composition of the different residues was analyzed with a Philips PW-2400 X-Ray spectrometer and a Philips PW-1710 DRX spectrometer, respectively.

\subsection{Dynamic viscosity measurements with sinusoidal oscillations}

The viscoelastic properties were determined using a Physica MCR 301 Rheometer with a coneand-plate geometry (CP25-1/True Gap). Samples were pre-heated to $60^{\circ} \mathrm{C}$ for $20 \mathrm{~min}$. The temperature was decreased to $20^{\circ} \mathrm{C}$ followed by a rest period of $20 \mathrm{~min}$ before starting the measurements. A strain amplitude sweep was carried out (from 0.01 to $100 \%$ ) using a fixed frequency of $10 \mathrm{rad} / \mathrm{s}$ to define the linear viscoelastic region and the yield stress values $(\mathrm{Pa})$. From the stress amplitude sweep, various viscoelastic parameters could be obtained. These include the complex modulus $\left(G^{*}\right)$, the elastic component $\left(G^{\prime}\right)$, the viscous component $\left(G^{\prime \prime}\right)$, and the yield stress values $\left(\gamma_{c}\right)$, that corresponds to the maximum stress (or strain) value under which the complex modulus still respond linearly to the applied strain.

\section{RESULTS AND DISCUSSION}

\subsection{Solid content determination}

\subsubsection{Modified ASTM procedure}

The solid content determination method was applied for five petroleum samples and the results are listed in Table 1. Petroleum samples 1 and 2 
Table 1. Solid content determined by ASTM 4807 method.

\begin{tabular}{cc}
\hline Petroleum Sample & Solid Content \\
\hline 1 & $0.07 \%$ \\
2 & $0.14 \%$ \\
3 & $0.06 \%$ \\
4 & $0.02 \%$ \\
5 & $0.03 \%$ \\
6 & $2.01 \%$ \\
\hline
\end{tabular}

and residues $A$ and $B$ were collected in the same process plant but from different collection points. In these cases, the solid contents were $0.07 \%$ and $0.14 \%$ for petroleum samples 1 and 2, respectively. The membranes are shown in Figure 1 . The presence of smaller particles is clearly seen for sample 1.

The solid content in sample $3(0.06 \%)$ suggests the presence of inorganic particles, as observed for samples 1 and 2 . However, in the image of the membrane obtained for this sample (Figure 1) there are no visible particles, as was verified for the other samples. A more detailed analysis by SEM/EDS indicated that the composition of the material retained on the membrane was only sodium chloride.

There were no significant differences between the solid contents of samples 1 and 3 (Table 1). Nevertheless, the visualization of the inorganic residues retained on the membranes indicates rather different results. For samples 4 and 5 , this is even more dramatic (Figure 2). For sample 4, with only $0.02 \%$ solid content, there are no visible particles and the residue is only sodium chloride, as was also verified for sample 3 . In the case of sample 5, a very distinct profile was observed. Comparisons between water insoluble particles that could affect emulsion stability and soluble compounds (such as sodium chloride) are very important in data interpretation using these kinds of procedures.

Focusing again on sample 1, after extraction of solids on the membrane with water, it was confirmed that $50 \%$ of the solids are soluble (probably, sodium chloride), which accounts for its rather low $0.07 \%$ solid content, considering only water-insoluble particles.

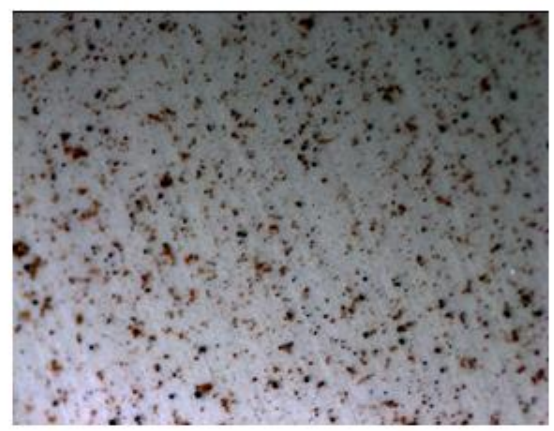

(2)

(1)

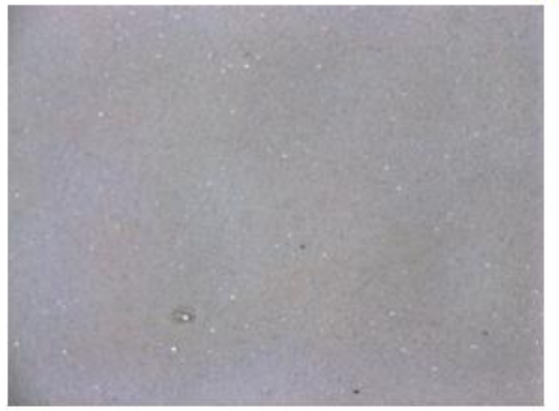

(3)

Figure 1. Images of membranes obtained for samples 1, 2 and 3. 
Qualitative comparison of membrane residues from samples 1 and 2 indicates higher concentration of particles in the filtration procedure for petroleum 1. Furthermore, the particles of sample 2 collected on the membrane are larger than other isolated particles. This is in agreement with the laboratory experiments involving emulsion samples of this type of petroleum. The emulsion prepared with petroleum 2 was not stable, and oil-water phase separation was verified with time. A more important parameter that affects the stability is particle size and not concentration (Sztukowski \& Yarranton, 2005). For sample 1 , whose separated particles are clearly smaller, emulsion samples collected in field operations are stable and phase separation is not detected. Therefore, it is evident how the mere observation of membranes can be useful in these analyses. In addition, it is necessary to establish proper correlations with the results obtained in this kind of analysis.
Table 2. Solid contents determined by sonication versus the ASTM 4807 method.

\begin{tabular}{ccc}
\hline \multirow{2}{*}{$\begin{array}{c}\text { Petroleum } \\
\text { Sample }\end{array}$} & \multicolumn{2}{c}{ Solid Content } \\
\cline { 2 - 3 } & Ultrasound & ASTM \\
\hline 2 & $0.06 \%$ & $0.07 \%$ \\
5 & $0.03 \%$ & $0.05 \%$ \\
\hline
\end{tabular}

A more dramatic case was observed with sample 6 . The solid content obtained by applying the modified ASTM procedure was around $2 \%$. However, no stable emulsion was observed associated with this sample. When the membrane was analyzed, it could be verified that only salt is present as spheres. A similar observation was reported by Cloud et al. (2007). However, in the present case, water droplets were retained in the membrane. Upon slow evaporation, salt crystals were formed in a spheroid configuration (Figure 3).

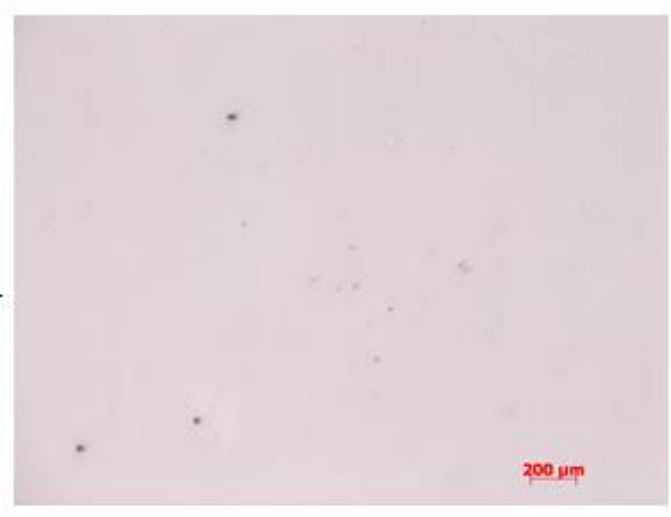

(4)

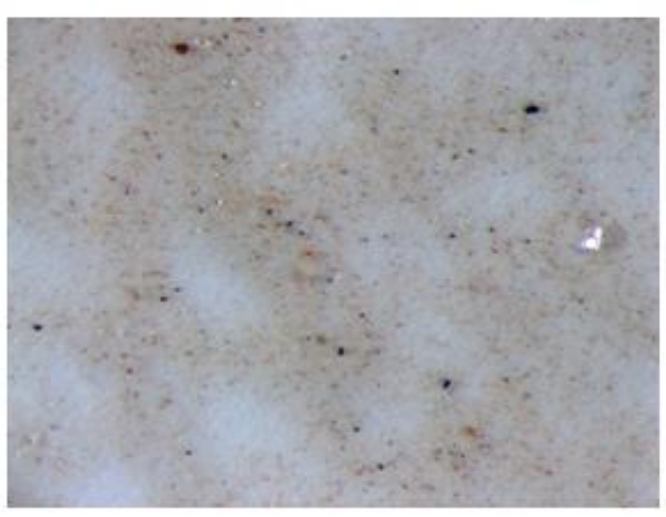

(5)

Figure 2. Membrane images obtained for samples 4 and 5.

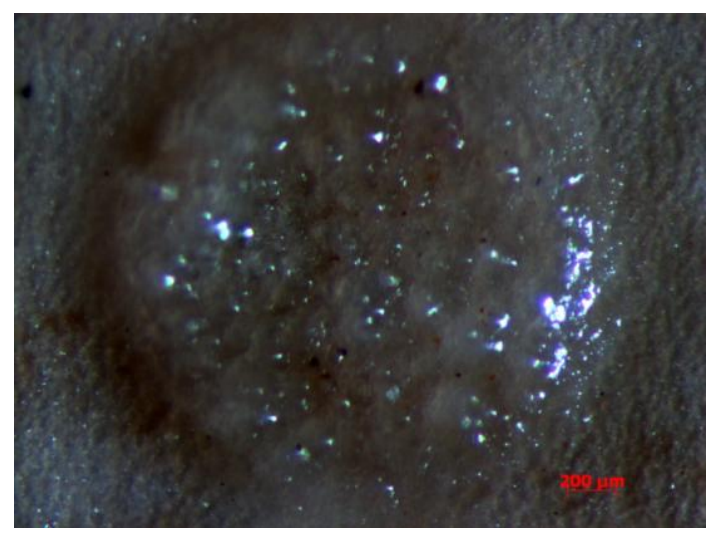

Figure 3. Solids (spheres) obtained for sample 6. 


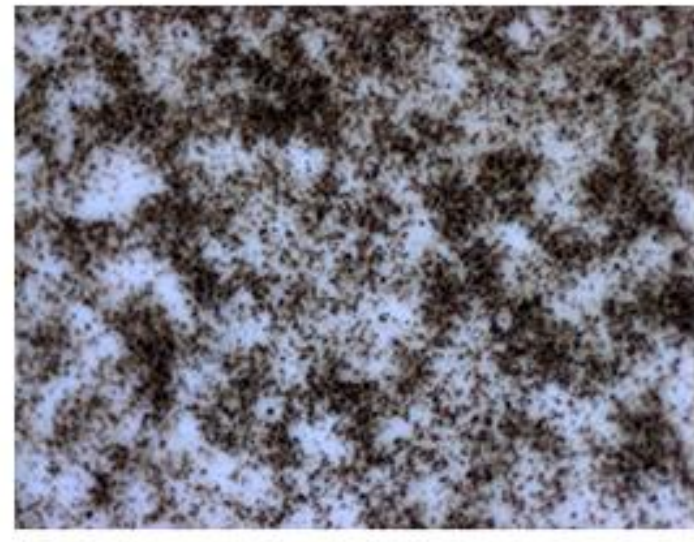

2 - ASTM

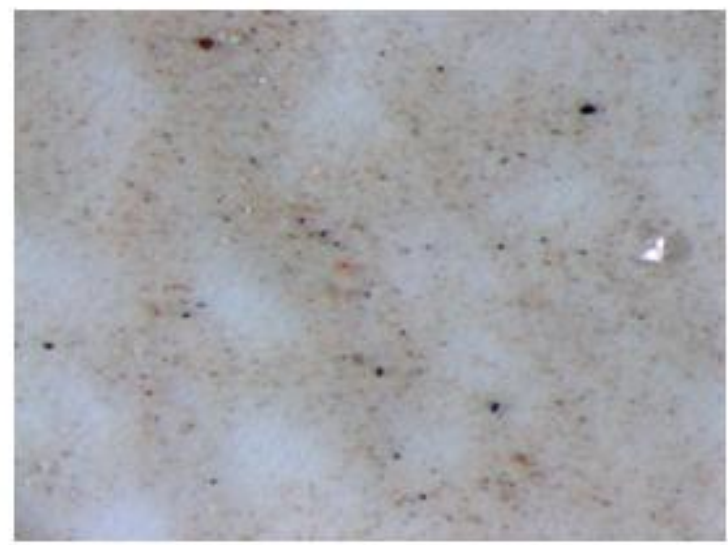

5 - ASTM

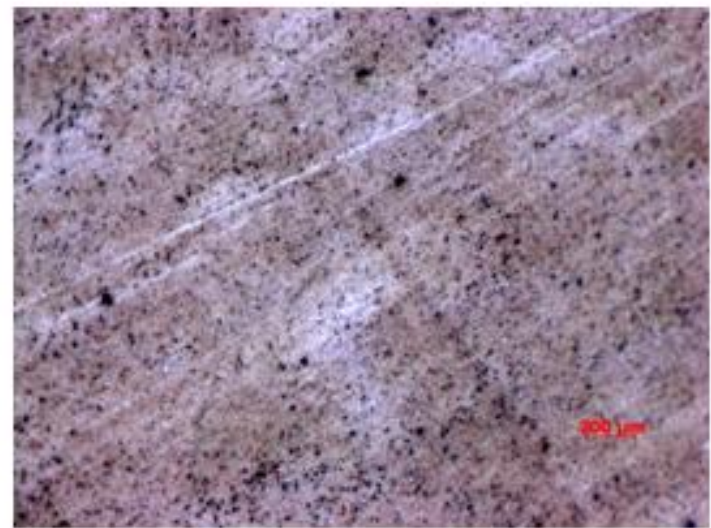

2 - Ultrasound

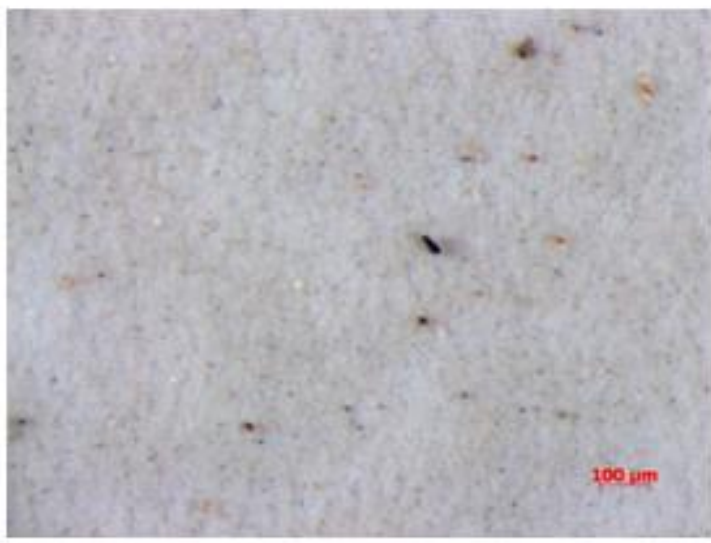

5 - Ultrasound

Figure 4. Images of samples 2 and 5 obtained in stereomicroscope with the ASTM and ultrasound-based procedures.

\subsubsection{Ultrasound-assisted procedure}

Sonication is mainly applied as a technique in an analytical procedure to enhance the effectiveness of particle dispersion in the solvent. In the ASTM conventional method, alteration of the media could induce more effective particle-particle interactions. These interactions result in larger particles due to clustering, which could be observed with sample 2 (Figure 1). The application of ultrasound procedure promotes solid dispersion, resulting in particles with minimum size. These kinds of particles are probably compatible, since emulsions could be eventually stabilized because of smaller particle sizes. This technique was applied with samples 2 and 5 and the results are shown in Table 2.

More importantly, one must carefully observe the material retained on the membranes. In the qualitative analyses, the comparison of membranes obtained after application of both methods suggests significant differences when visible particles are detected. In Figure 4, one can see that solids were formed as aggregates (ASTM procedure). For sample 2, this effect is more pronounced. In the ultrasound-based procedure, the separated particles were smaller and dispersed. Also, the membrane color was brown, probably due to adsorption of the polar petroleum compounds on the membrane. These organic compounds might also be adsorbed on solids in the original sample.

The size of the solid particles separated during the ultrasound procedure for sample 2 was measured by SEM/EDS. The comparative results between the membranes in the SEM analysis reinforce the data obtained by membrane visualization using the stereomicroscope. In Figure 5 , observation of the membrane obtained with the ultrasound technique indicates that the particles 


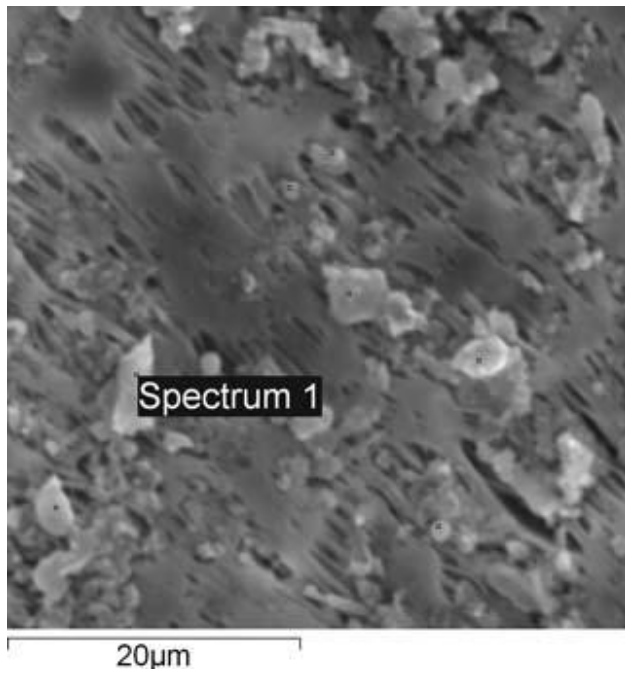

Figure 5. SEM image of sample 2 obtained with the ultrasound-based procedure.

are very small and dispersed. Some elements could be detected as marked points (spectrum 1), namely calcium, iron, sulfur, silicon, magnesium, aluminum, sodium and chlorine. The maximum particle size was $0.5 \mu \mathrm{m}$. Because these data were not acquired by direct measurements, it was not possible to associate the particle size with a specific type of solid present in the petroleum samples. However, it is possible that some solids could adsorb at interfaces and act as emulsion stabilizers. The range of particle sizes obtained in this work is compatible with the data reported by Sztukowski \& Yarranton (2005).

\subsection{Characterization of the sludge samples}

\subsubsection{Chemical characterization}

Sludge samples A and B were collected in the producing plant of petroleum 1 . The occurrence of residues in this system was usual and, because of its solid content, this could be a possible explanation to the problems observed. The results of the chemical characterization of sludge samples $A$ and $B$ are presented in Table 3.

In both samples, the amount of inorganic materials is over $40 \%$, with a majority of corrosion

Table 3. Results obtained in chemical characterization procedure to sludge samples $A$ and $B$.

\begin{tabular}{|c|c|c|c|c|}
\hline \multirow{2}{*}{ Soluble Fraction } & \multicolumn{2}{|r|}{ Sample A } & \multicolumn{2}{|r|}{ Sample B } \\
\hline & Yield (\%) & Results & Yield (\%) & Results \\
\hline n-Hexane & 50 & Aliphatic hydrocarbons & 12 & Aliphatic hydrocarbons \\
\hline Toluene & 6 & $\begin{array}{c}\text { Aromatic fraction } \\
\text { profile }\end{array}$ & 24 & Presence of demulsifier \\
\hline Dichloromethane & - & - & - & - \\
\hline Insoluble & 42 & $\begin{array}{l}\text { Elements detected: } \\
\text { iron, sulfur and silicon. } \\
\text { Compounds observed: } \\
\mathrm{Fe}_{3} \mathrm{O}_{4}, \mathrm{SiO}_{2} \text { and } \mathrm{Fe}_{3} \mathrm{~S}_{4}\end{array}$ & 44 & $\begin{array}{l}\text { Elements detected: silicon, } \\
\text { aluminum and iron. Compounds } \\
\text { observed: } \mathrm{SiO}_{2},\left(\mathrm{Na}\left(\mathrm{Si}_{3} \mathrm{Al}\right) \mathrm{O}_{8}\right), \\
\left.\left((\mathrm{Na}, \mathrm{K}) \mathrm{Si}_{3} \mathrm{Al}\right) \mathrm{O}_{8}\right) \\
\left(\mathrm{Ca}_{5} \mathrm{Si}_{6} \mathrm{O}_{16}(\mathrm{OH})_{2}\right), \\
\left(\mathrm{Ca}_{10}\left(\mathrm{SiO}_{4}\right)_{3}\left(\mathrm{SO}_{4}\right)_{3} \mathrm{Cl}_{2}\right)\end{array}$ \\
\hline Non-recoverable & 2 & - & 20 & - \\
\hline
\end{tabular}




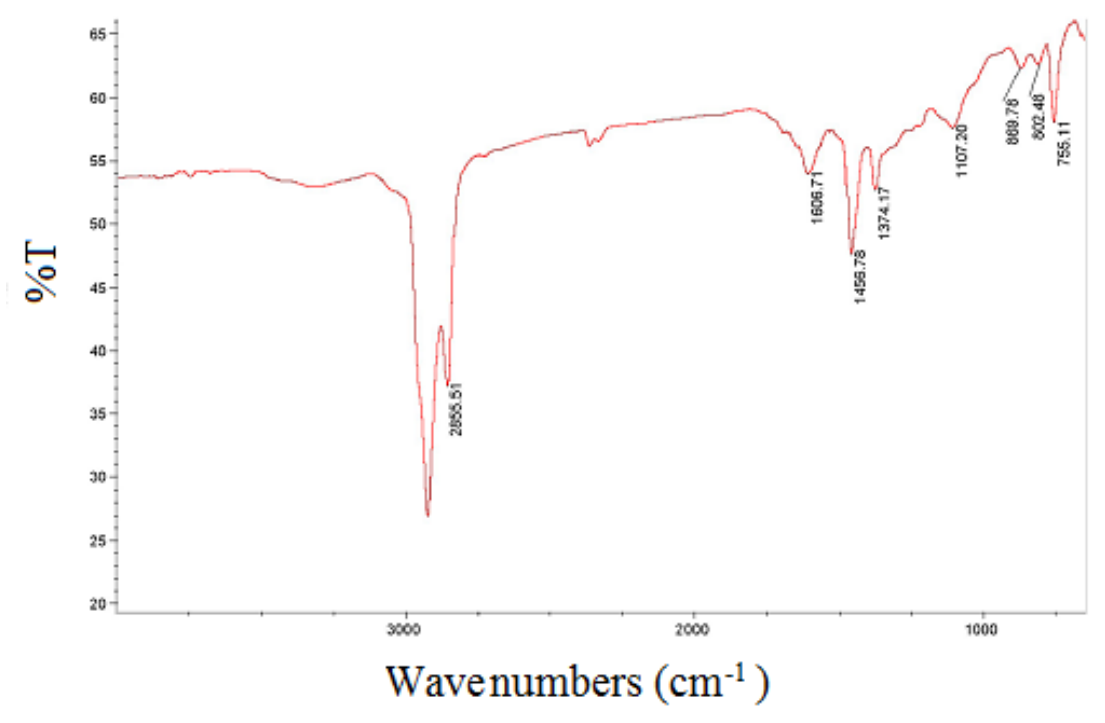

Figure 6. Infrared spectrum obtained from toluene soluble fraction of sludge sample A.

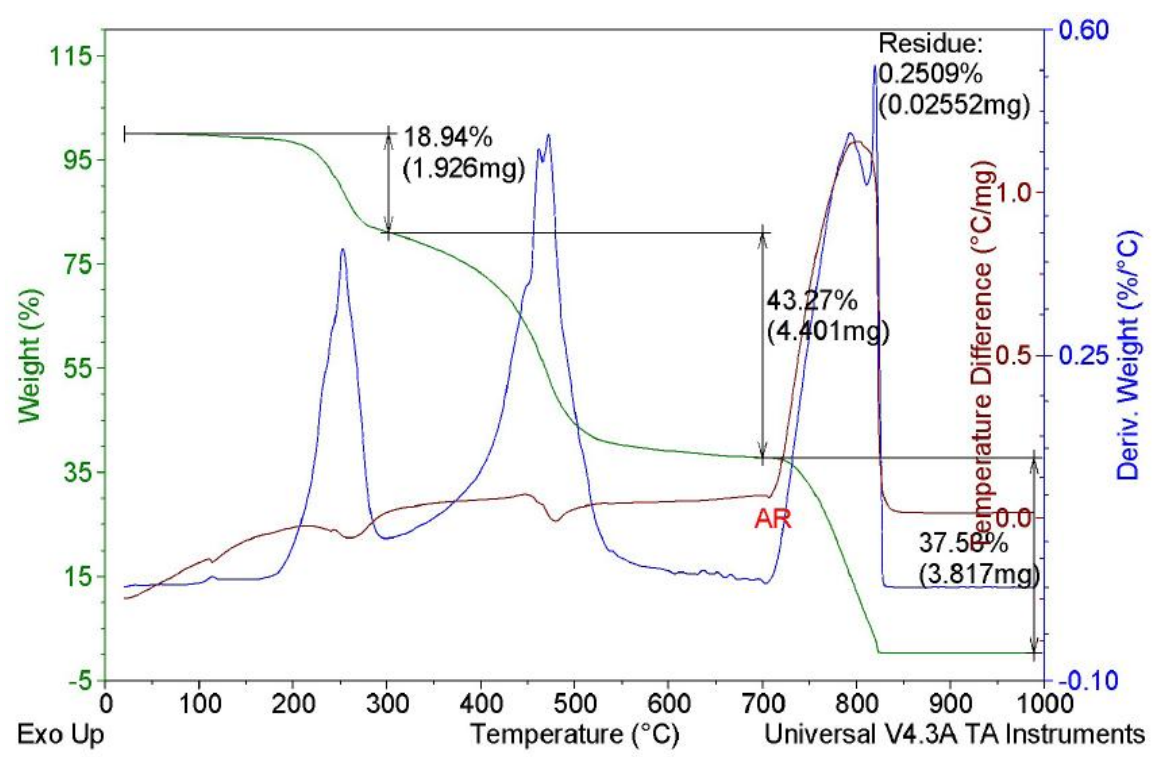

Figure 7. Thermogravimetric analysis obtained from toluene soluble fraction of sample A.

products (sample A) and formation rocks (sample B). The presence of polar species was also detected for both samples (toluene extracts). This species could have been adsorbed on the solid surface altering its properties, as described in other studies (Hannisdal et al., 2006; Kowalewski et al., 2002; Sztukowski \& Yarranton, 2005). Reports show that highly stable emulsion occurs when solids with intermediate hydrophobicity are present at the water-oil interface (Sztukowski \& Yarranton, 2005; Yan et al., 2001). For sample A, the infrared spectrum of the toluene soluble fraction indicates an aromatic composition that could be attributed to asphaltenes (Figure 6; wavenumber $1600 \mathrm{~cm}^{-1}$ attributed to the axial $C=C$ bond present in aromatic compounds).

To confirm this hypothesis, the toluene soluble fraction was submitted to thermogravimetric analysis. The results shown in Figure 7 are compatible with an asphaltene composition, as reported in the literature (Teixeira \& Gonçalves, 2001). Considering the asphaltene concentration in crude oil for this system (2.4\%), higher concentration of these compounds could be observed with sample A (6\% in toluene fraction). 


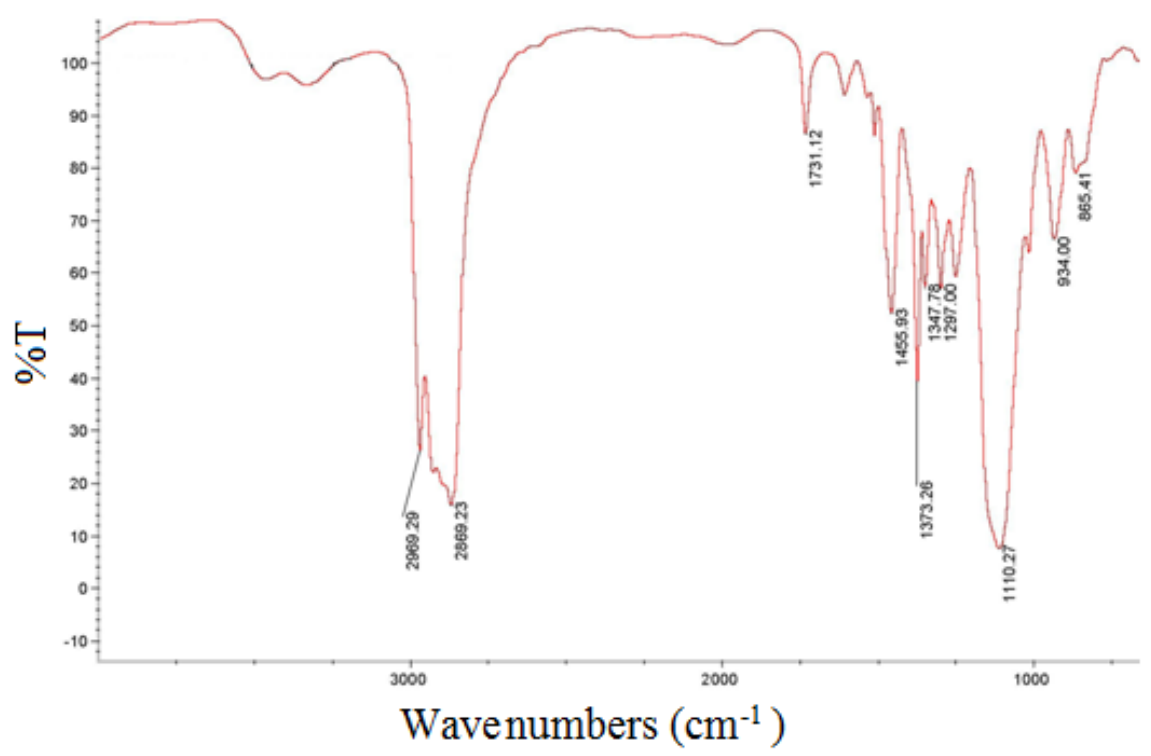

Figure 8. Infrared spectra obtained from toluene soluble fraction of sample B.

In sample $B$, the toluene fraction yield was higher than 20\%, which could indicate high asphaltene concentration. However, the observation of a band around $1110 \mathrm{~cm}^{-1}$ in the infrared spectrum suggests a C-O bond (Figure 8), typically found in the demulsifier compounds used in the process (in this case, a propoxylatedethoxylated copolymer).

If one considers the composition of toluene fraction in samples $A$ and $B$, there are two possible causes for residue formation:

1. The dosage of demulsifier or the formulation of the applied demulsifier is out of an ideal range (this was probably the main cause with sample B). In this situation, oil-water phase separation is not fast enough, forming non-resolved interfaces. Emulsion stabilizers (asphaltene and other polar components), inorganic solid particles and demulsifiers are present at this interface, and cause sludge accumulation with time. The effect of the demulsifier formulation and its interaction with asphaltenes in a non-ideal range was reported by Rondon et al. (2006; 2008).

2. Polar compounds present in the oil and chemical additives could interact with inorganic solids, resulting in aggregation phenomena (this was probably the main cause with sample A). As a result, sludge formation would be observed with high concentration of solids associated with the presence of the organic components cited above. A similar hypothesis was studied by Zahabi et al. (2010) in model oil solutions. It was observed that the interaction between asphaltenes and silica particles results in the flocculation of solid particles, which could be used as a method for solid removal.

Sludge samples C and D are semi-solid and were centrifuged to promote solid separation. More than $70 \%$ of water content was determined in both samples. The solid residues obtained in the centrifugation procedure were analyzed. The results are presented in Tables 4 and 5 . The yields obtained in the extraction procedure were calculated as a function of the initial total mass of the sample before centrifugation. Sample D was collected in the refinery (separator tank) where petroleum 2 was processed.

Both samples could be considered as emulsion systems. Previously, sample $C$ was centrifuged at $3,000 \mathrm{rpm}(1,000 \mathrm{~g})$ and no phase separation was observed. The emulsion was detected only when the centrifugation procedure was carried out at $12,000 \mathrm{rpm}(15,455 \mathrm{~g})$, which suggests the higher stability of this emulsion system (Figure 9). In sample D, inorganic compounds were detected, mainly iron sulfide and oxides. Iron sulfide species are potential emulsion stabilizers due to their great 
Table 4. Results obtained from the chemical characterization procedure of sample C.

\begin{tabular}{ccc}
\hline Soluble Fraction & Yield (\%) & Results \\
\hline n-Hexane & 8 & Aliphatic hydrocarbons \\
Toluene & 2 & Presence of demulsifier \\
Dichloromethane & - & - \\
Insoluble & 14 & Elements detected: iron, sulfur, calcium and barium Compounds \\
observed: $\mathrm{Fe}_{2} \mathrm{O}_{3}, \mathrm{CaCO}_{3}$ and $\mathrm{BaSO}_{4}$. \\
Non-recoverable & 76 & Mostly water $^{2}$
\end{tabular}

Table 5. Results obtained from the chemical characterization procedure of sample D.

\begin{tabular}{ccc}
\hline Soluble Fraction & Yield (\%) & Results \\
\hline Hexane & 18 & Aliphatic hidrocarbons \\
Toluene & $<1$ & Aromatic hidrocarbons and naphtenic acids \\
Dichloromethane & - & - \\
Insoluble & 4 & Elements detected: iron, sulfur and calcium Compounds \\
observed: $\mathrm{Fe}_{2} \mathrm{O}_{3}, \mathrm{FeO}(\mathrm{OH}), \mathrm{FeS}$ \\
Non-recoverable & 81 & Mostly water \\
\hline
\end{tabular}

capacity to interact with the oil-water interface (Lehmann \& Firouzkouhi, 2008). However, when submitted to centrifugation at 3,000rpm, phase separation was observed, which suggests that emulsion sample $C$ is more stable than $D$, which could be related to a higher solid concentration in

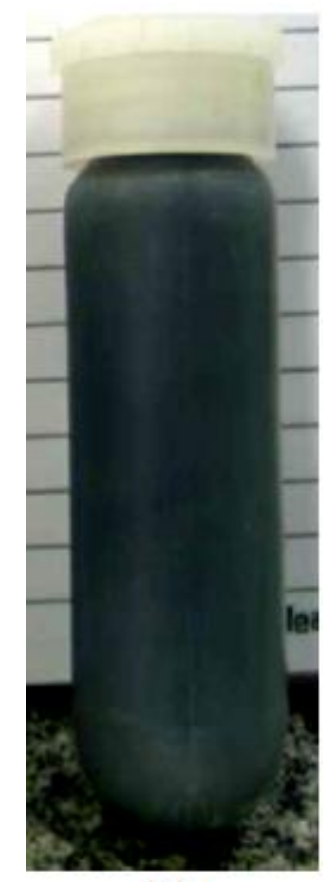

(A)

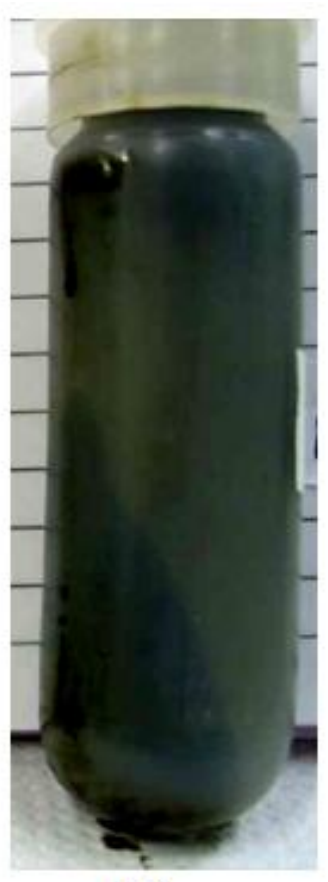

(B)
Figure 9. Emulsion $C$ centrifuged at 3,000 rpm (A); Emulsion $C$ centrifuged at 12,000 rpm (B); Decanted solids were observed at the bottom of tube $B$. sample $C$. Considering the sludge formation mechanism discussed before for samples $A$ and $B$, in these cases the concentration of polar components was low, which could explain the semi-solid characteristics observed.

\subsubsection{Dynamic measurements with sinusoidal oscillations}

Rheological dynamic measurements were performed for all sludge samples. The curves are shown in Figures 10 and 11 and for all samples the following behaviors were confirmed:

- $\mathrm{G}^{\prime}$ is higher than $\mathrm{G}^{\prime \prime}$ over a significant shear stress range;

- The high yield stress values can be attributed to the high concentration of solid particles in these samples (see Table 6).

The rheological properties of the four sludge samples are typical of viscoelastic systems, but with a predominant elastic component, almost to

Table 6. Yield stress values determined by oscillatory experiments.

\begin{tabular}{c|c}
\hline Sludge & Yield Stress / Pa \\
\hline $\mathrm{A}$ & 4.7 \\
\hline $\mathrm{B}$ & 52.8 \\
\hline $\mathrm{C}$ & 131.0 \\
\hline $\mathrm{D}$ & 1.05 \\
\hline
\end{tabular}




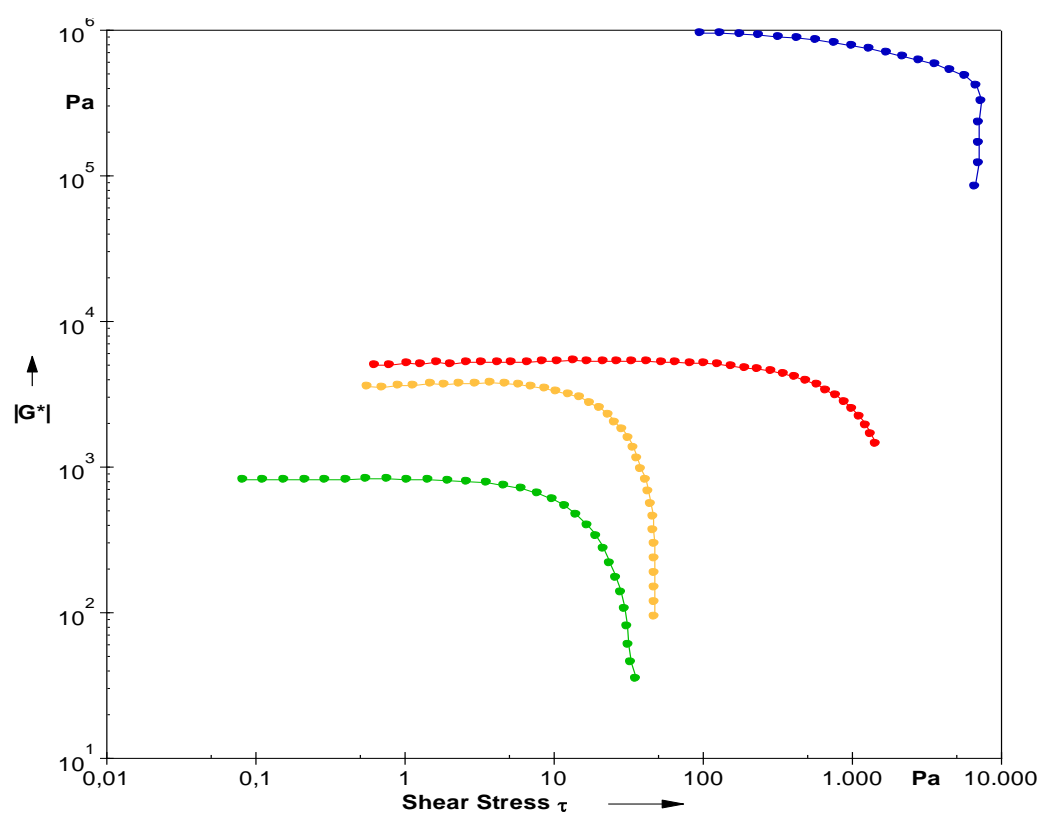

Figure 10. Complex modulus of samples A (yellow), B (red), C (blue) and D (green) as a function of shear stress (frequency $=10 \mathrm{rad} / \mathrm{s}$ ).

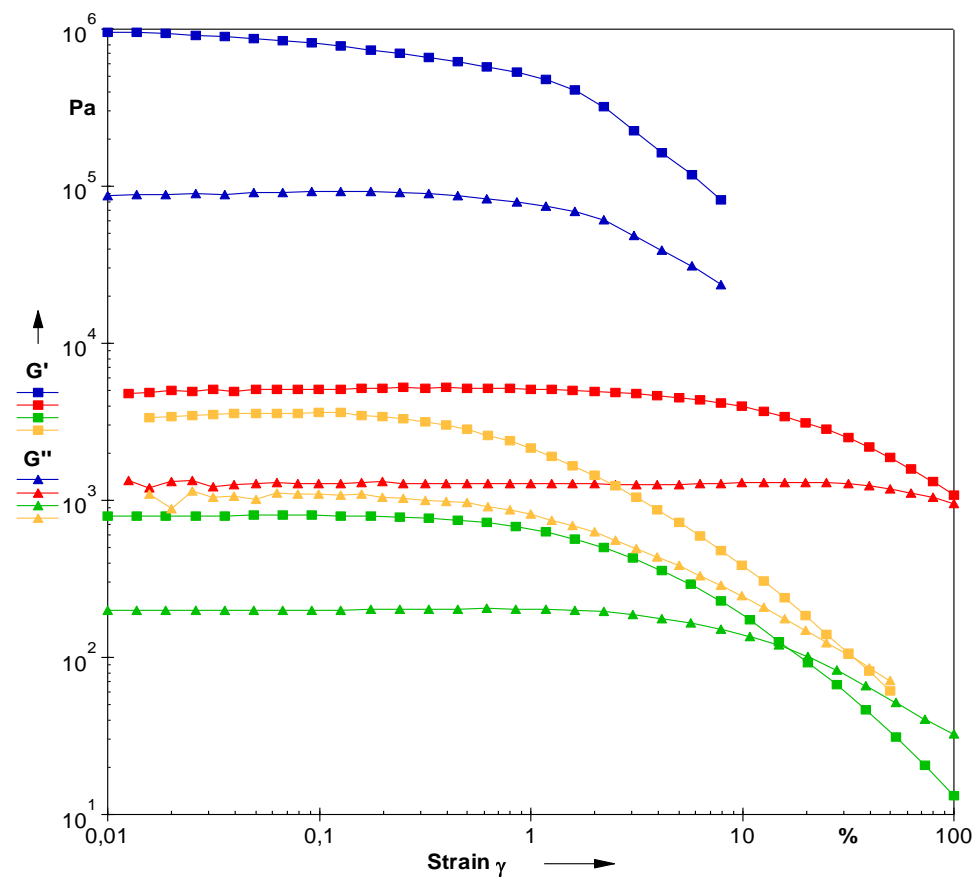

Figure 11. Storage modulus (squares) and loss modulus (triangles) of samples A (yellow), B (red), C (blue) and D (green) as a function of strain (frequency $=10 \mathrm{rad} / \mathrm{s}$ ).

one order of magnitude. This suggests that the system is essentially solid-like, as well as stable in terms of phase separation, indicating the presence of strong interaction forces.

The differences observed in the complex modulus and yield stress values can be attributed to the specific composition of the samples, including the water content, solid particles, hydrocarbons and chemicals present. Aging history is also an important factor referring to sludge rheological properties. In fact, sludge obtained from field samples can be difficult to characterize, since there are complex structures involved. Many authors used different methodologies to study 
these kinds of systems, which led to different theories, all of which, however, with significant limitations (Saiki et al., 2008; Svetlana, 2009; Torres et al., 2007).

Rheometry is an important tool to distinguish the two viscoelastic components (viscous and elastic), which allows to predict with reasonable precision the system behavior in terms of kinetic stability or phase separation. Comparing the rheological behaviors of samples $A$ and $B$, which were originated from the same crude oil and presented similar insoluble particles, it is evident how much the presence of chemicals (such as demulsifiers) can impact the system yield stress (see Table 6). The yield stress of sample B (52.8Pa) is more than ten times higher than the yield stress of sample $A(4.74 \mathrm{~Pa})$, although they are composed of the same oil. The network formed in sample B and its predominant elastic behavior can be related to self-assembly originated from demulsifier molecules.

Sample $\mathrm{C}$ had the higher yield stress value among the samples studied (131Pa). This sample has the lower aliphatic hydrocarbon content also $(8 w t \%)$, and is one of those with the highest water content ( $>60 \mathrm{wt} \%$ ). Besides its liquid phase composition, sample $\mathrm{C}$ comprises a variety of inorganic scales, such as $\mathrm{CaCO}_{3}$ and $\mathrm{BaSO}_{4}$, which can corroborate its higher elastic behavior (Bressy et al., 2003). In this case, the presence of polar components (demulsifiers) together with inorganic fine particles at the interface as verified in the chemical characterization could relate to the high yield stress obtained. In sample $D$, the yield stress is lower than in sample C. It is possible that this correlates with the lower stability of this sample as observed in the centrifugation procedures.

\subsection{Solid content versus sludge formation}

Despite all data discussion regarding solid contents of petroleum $1(0.14 \%)$ and $2(0.07 \%)$ and occurrence and analysis of sludge (samples A, B, and $C$ ), it is not clear if oils with the solid contents reported are capable of forming residues with such high inorganic concentrations. In view of this, two oil samples were collected in a refinery in two different situations: Normal operation, with no related occurrences (Petroleum 7); and Abnormal operation, with problems observed during desalting with higher BSW detected in the oil after processing (Petroleum 8). The solid content of

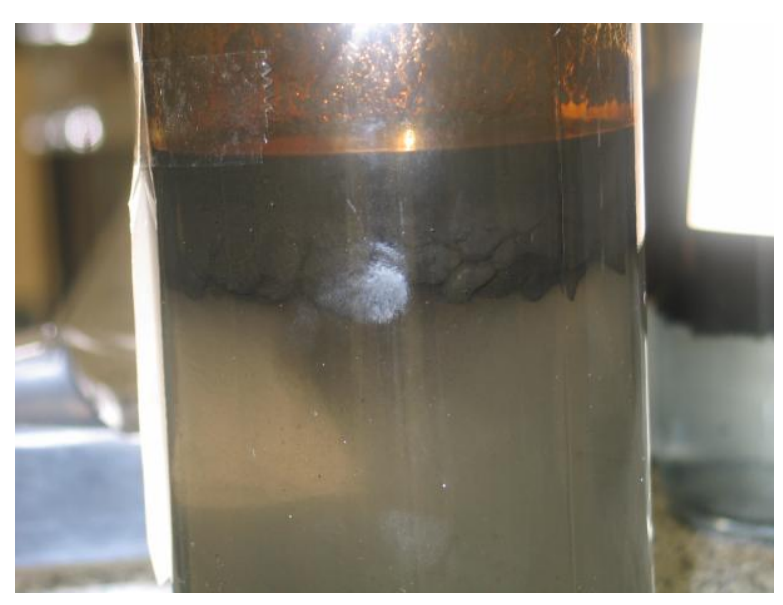

Figure 12. Rag layer observed in sample F collected in the desalting equipment.

petroleum samples 7 and 8 are, respectively, $0.01 \%$ and $0.20 \%$.

The solid content observed in petroleum 7 could be considered low, as reported in the literature (Cloud et al., 2005). With regard to petroleum sample 8 , the solid content is more than twenty times higher. This result could be an explanation to problems reported during petroleum refining. Additionally, water-oil emulsions were collected in desalting equipment during refining of oils 7 and 8 to prove the solid hypothesis (Sample E during refining of petroleum 7 and Sample $F$ during refining of petroleum 8 ). In sample $E$, a welldefined rag layer was not observed. A totally different scenario was detected with sample $F$, as shown in Figure 12.

The rag layers separated in both samples were centrifuged. For sample $E$, the presence of solids was not observed. This is an evidence that the solid contents in Petroleum 7 are low and probably do not affect crude oil refining. With sample $F$, the presence of solids after the centrifugation procedure was detected. The results obtained for the analysis of the separated solid residues are detailed in Table 7. The reported yield was normalized considering the centrifuged rag layer mass.

Considering the initial interface sample, a solid stabilized emulsion was probably formed, based on the high inorganic concentration determined in the analysis of rag layer F. Besides the inorganic compounds detected, as mentioned above, iron sulfide compounds are potential emulsion 
Table 7. Results obtained in solids separated analysis from rag layer F.

\begin{tabular}{|c|c|c|}
\hline Fractions & Yield & Results \\
\hline n-Hexane soluble & $32.1 \%$ & Infrared: spectrum compatible with hydrocarbons. \\
\hline Toluene soluble & $0.6 \%$ & $\begin{array}{l}\text { Infrared: spectrum compatible with aromatic species and } \\
\text { demulsifier }\end{array}$ \\
\hline $\begin{array}{l}\text { Dichloromethane } \\
\text { soluble }\end{array}$ & $0.1 \%$ & $\begin{array}{l}\text { Infrared: spectrum compatible with aromatic species and } \\
\text { demulsifier }\end{array}$ \\
\hline \multirow[t]{2}{*}{ Insoluble (inorganic) } & $3.5 \%$ & $\begin{array}{l}\text { X-ray fluorescence: iron (20\%), silicion (9\%), sulfur (9\%), } \\
\text { calcium (6\%), aluminum (5\%), barium (4\%) and magnesium } \\
(2 \%) .\end{array}$ \\
\hline & & $\begin{array}{l}\text { X-ray difraction: gypsum }\left(\mathrm{CaSO}_{4} \cdot \mathrm{H}_{2} \mathrm{O}\right) \text {, barite }\left(\mathrm{BaSO}_{4}\right) \text {, } \\
\text { hematite }\left(\mathrm{Fe}_{2} \mathrm{O}_{3}\right) \text {, quartz }\left(\mathrm{SiO}_{2}\right) \text {, troilite }(\mathrm{FeS}) \text {, and calcite } \\
\qquad\left(\mathrm{CaCO}_{3}\right)\end{array}$ \\
\hline Non-recuperable & $63.7 \%$ & Probably water and volatile compounds \\
\hline
\end{tabular}

stabilizers due to their great capacity to interact with the oil-water interface (Lehmann \& Firouzkouhi, 2008).

Aromatic compounds (probably associated with asphaltenes) and other chemicals (demulsifiers added to promote emulsion separation) were detected in toluene-soluble extracts. Asphaltenes are known to be natural petroleum compounds capable of stabilizing emulsions (Yang et al., 2007). Desemulsifiers can interact with asphaltenes at the water-oil interface, thereby reducing the interfacial tension (Rondon et al., 2008). Asphaltenes and demulsifiers could also interact with inorganic compounds, forming solids with intermediate hydrophobicity and capable of migrating to the water-oil interface (Sztukowski and Yarranton, 2005).

Solids present in petroleum sample $\mathrm{F}$ probably are concentrated at the interface (emulsion layer) inside the desalting equipment, forming a more stable emulsion. The higher stability induces higher concentration of inorganic compounds at the interface during the equipment operation. The thickness of the emulsion layers in the desalter could be enlarged and separated oil or water could be incorporated, causing problems during operation. This phenomenon is probably similar to the one described for sample B. This was not observed with sample $E$ because the inorganic solid content is low. Therefore, it was impossible to form a more stable emulsion in this case.

\section{CONCLUSIONS}

Considering all data and discussion reported in this article, it is possible to make the following observations:

- Application of modified ASTM method in the determination of solid contents could result in aggregated particles. Application of ultrasound could disperse the solids, resulting in particles with sizes that could be compatible with emulsion stabilizers.

- The presence of polar compounds, such as asphaltenes or demulsifiers, and inorganic particles at the water-oil interface under specific conditions, such as non-ideal concentrations of demulsifiers or high concentrations of asphaltenes and inorganic particles, could induce the formation of rag layers at the interface (this happened with Sample $F$ in this work). This layer can become more dense with time, generating the slugdes observed in this work (samples A and B).

- As far as solid-stabilized emulsions are concerned (samples C, D, and F), stability depends on solid content (higher for sample C and F). In the case of sample $F$, it was observed a relationship with high solid content in petroleum during refining process (sample 8).

- From the dynamic oscillatory assays, one could conclude that, because of the specific composition of the samples, which comprise 
inorganic particles associated with highmolecular weight hydrocarbons, an elastic network was developed which caused differences in the complex modulus and yield stress, and therefore in the stability of the system, thereby inducing phase separation.

\section{REFERENCES}

Bressy, L.; Hebraud, P.; Schmitt, V.; Bibette, J.. Rheology of Emulsions Stabilized by Solid Interfaces. Langmuir. v. 19, 598-604, 2003. http://dx.doi.org/10.1021/la0264466

Brons, C.; Varadaraj, R. Molecular Origins of Heavy Crude Oil Interfacial Activity Part 2: Fundamental Interfacial Properties of Model Naphthenic Acids and Naphthenic Acids Separated from Heavy Crude Oils. Energy and Fuels. v. 21, p. 199-204, 2007. http://dx.doi.org/10.1021/ef060425s

Cloud, R. W.; Marsh, S. C.; Samaniego-Linares, S.; Poindexter, M. K. Further Investigations into the Nature of Salt Spheres and Inorganic Structures at the Crude Oil-Water Interface. Energy and Fuels. v. 24, p. 2376-2382, 2010.

http://dx.doi.org/10.1021/ef901063e

Gafonova, O. V.; Yarranton, H. W. The Stabilization of Water-in-Hydrocarbon Emulsions by Asphaltenes and Resins. Journal of Colloid and Interface Science. v. 241, p. 469-478, 2001.

http://dx.doi.org/10.1006/jcis.2001.7731

Hannisdal, A.; Ese, M. H.; Hemmingsen, P. V.; Sjoblom, J. Particle-Stabilized Emulsions: Effect of Heavy Crude Oil Components Pre-Adsorbed onto Stabilizing Solid. Colloids and Surfaces A. Physicochemical Engineering Aspects. v. 276, p. 45-58, 2006.

http://dx.doi.org/10.1016/i.colsurfa.2005.10.011

Kilpatrick, P. K.; Sullivan, A. P. The Effects of Inorganic Solid Particles on Water and Crude Oil Emulsion Stability. Industrial Engineering Chemical Research. v. 41, p. 3389-3804, 2002. http://dx.doi.org/10.1021/ie010927n
Kowalewski, E.; Holt, T.; Torsaeter, O. Wettability Alterations Due to an Oil Soluble Additive. Journal of Petroleum Science and Engineering. v. 33, p. 19-28, 2002.

http://dx.doi.org/10.1016/S0920-4105(01)00172-3

Lehmann, M.; Firouzkouhi, F. A New Chemical Treatment to Inhibit Iron Sulfide Deposition. Society of Petroleum Engineers. Society of Petroleum Engineers. SPE 114065, p. 1-31, 2008.

Marsh, S. C.; Poindexter, M. K. Inorganic Solid Content Governs Water-in-Crude Oil Emulsion Stability Predictions. Energy and Fuels. v. 23, p. 1258-1268, 2009.

http://dx.doi.org/10.1021/ef800652n

Martos, C.; Coto, B.; Espada, J. J.; Robustillo, M.D.; Peña, J. L.; Merino-Garcia, D. Characterization of Brazilian Crude Oil Samples To Improve the Prediction of Wax Precipitation in Flow Assurance Problems. Energy and Fuels. v. 24, p. 2221-2226, 2010.

http://dx.doi.org/10.1021/ef900784w

Oliveira, M. C. K.; Carvalho, R. M.; Carvalho, A. B.; Couto, B. C.; Faria, F. R. D.; Cardoso, R. L. P. Waxy Crude Oil Emulsion Gel: Impact on Flow Assurance. Energy and Fuels. v. 24, p. 2287-2293, 2010. http://dx.doi.org/10.1021/ef900927g

Poindexter, M. K., Chuai, S., Marble, R. A., Marsh, S. C. Solid content Dominates Emulsion Stability Predictions. Energy and Fuels. v. 19, p. 1346-1352, 2005.

http://dx.doi.org/10.1021/ef049797w

Ramirez-Jaramillo, E.; Lina-Galeana, C.; Manero, O. Modeling Asphaltene Deposition in Production Pipelines. Energy and Fuels. v. 20, p. 1184-1196, 2006. http://dx.doi.org/10.1021/ef050262s

Rondon, M.; Bouriat, P.; Lachaise, J.; Salager, J. L. Breaking of Water-in-Crude Oil Emulsions. 1. Physicochemical Phenomenology of Demulsifier Action. Energy and Fuels. v. 20, p. 1600-1604, 2006. http://dx.doi.org/10.1021/ef060017o

Rondon, M.; Pereira, J. C.; Bouriat, P.; Gracia, A.; Lachaise, J.; Salager, J. L. Breaking of Water-inCrude-Oil Emulsions. 2. Influence of Asphaltene Concentration and Diluent Nature on Demulsifier Action. Energy and Fuels. v. 22, p. 702-707, 2008. http://dx.doi.org/10.1021/ef7003877 
Saiki, Y.; Horn, R. G.; Prestidge, C. A. Rheological transition of concentrated emulsions during successive shearing cycles. Journal of Colloid and Interface Science, v. 327, p. 440-442, 2008. http://dx.doi.org/10.1016/i.jcis.2008.08.034

Svetlana, R. D. Rheology of emulsions. Advances in Colloid and Interface Science, v. 151, p. 1-23, 2009. http://dx.doi.org/10.1016/i.cis.2009.07.001

Sztukowski, D. M.; Yarranton, H. W. Oilfield Solids and Water-in-Oil Stability. Journal of Colloid and Interface Science. Journal of Colloid and Interface Science. v. 285, p. 821-833, 2005. http://dx.doi.org/10.1016/i.jcis.2004.12.029

Teixeira, M. A. G.; Gonçalves, M. L. A. The combination of thermal analysis and supercritical extraction as a tool for characterization of mixed deposits and sludges. Journal of Petroleum Science and Engineering. Journal of Petroleum Science and Engineering. v. 32, p. 249-255, 2001. http://dx.doi.org/10.1016/S0920-4105(01)00165-6

Torres, L. G.; Iturbe, R.; Snowden, M. J.; Chowdhry, B. Z.; Leharne S. A. Preparation of o/w emulsions stabilized by solid particles and their characterization by oscillatory rheology. Colloids and Surfaces A, v. 302, p. 439-448, 2007. http://dx.doi.org/10.1016/j.colsurfa.2007.03.009
Wang, J.; Yin, J.; Ge, L.; Shao, J.; Zheng, J. Characterization of Oil Sludges from Two Oil Fields in China. Energy and Fuels. v. 24, p. 973-978, 2010. http://dx.doi.org/10.1021/ef900925a

Yan, N.; Gray, M. R.; Masliyah, J. H. On Water-inOil Emulsions Stabilized by Fine Solids. Colloids and Surfaces A. Physicochemical Engineering Aspects. v. 193, p. 97-107, 2001. http://dx.doi.org/10.1016/S0927-7757(01)00748-8

Yang, X.; Verruto, V. J.; Kilpatrick, P. K. Dynamic Asphaltene-Resin Exchange at the Oil/Water Interface: Time-Dependent W/O Emulsion Stability for Asphaltene/Resin Model Oils. Energy and Fuels. v. 21, p. 1343-1349, 2007.

http://dx.doi.org/10.1021/ef060465w

Zahabi, A.; Gray, M. R.; Czarnecki, J.; Dabros, T. Flocculation of silica particles from a model oil solution. Effect of adsorbed asphaltenes. Energy and Fuels. v. 24, p. 3616-3623, 2010. http://dx.doi.org/10.1021/ef100079j 